Article

\title{
Digital Inability and Social Sustainability in the Face of the Fourth Industrial Revolution: A Proposal of New Non-Financial Indicators
}

\author{
Alvaro Guitart Martín ${ }^{1, *}$ and Ricardo J. Palomo Zurdo ${ }^{2, *}$ \\ 1 CEINDO-CEU Doctoral Program in Economy \& Law, Universidad CEU San Pablo, 28003 Madrid, Spain \\ 2 School of Business and Economics, Universidad CEU San Pablo, 28003 Madrid, Spain \\ * Correspondence: alvaro.guitartmartin@usp.ceu.es (A.G.M.); palzur@ceu.es (R.J.P.Z.)
}

Citation: Guitart Martín, A.; Palomo Zurdo, R.J. Digital Inability and Social Sustainability in the Face of the Fourth Industrial Revolution: A Proposal of New Non-Financial Indicators. Sustainability 2021, 13, 13958. https://doi.org/10.3390/ su132413958

Academic Editors: Gohar Khan, Hangjung Zo and Feroz Abdul Karim

Received: 24 October 2021

Accepted: 14 December 2021

Published: 17 December 2021

Publisher's Note: MDPI stays neutral with regard to jurisdictional claims in published maps and institutional affiliations.

Copyright: (c) 2021 by the authors. Licensee MDPI, Basel, Switzerland. This article is an open access article distributed under the terms and conditions of the Creative Commons Attribution (CC BY) license (https:/ / creativecommons.org/licenses/by/ $4.0 /)$.

\begin{abstract}
In the knowledge economy, financial indicators are not sufficient to predict the evolution of business competitiveness and anticipate risks. This paper proposes new non-financial indicators based on the analysis of eighteen variables representative of the interest of the different stakeholders, which correlate the organization's commitment to socially sustainable digital transformation and the enhancement of business capabilities. This study, based on a specific adaptation of the IMPACT methodology and carried out in forty countries, obtains as main findings that there are significant differences in the perception of the business impact generated by the improvement of the digital capabilities of the workforce according to variables, such as job level, area of work, cultural area of the interviewee, type of company, or the number of years that digital training programs have been implemented among the workforce, while factors, such as gender or generation of the interviewee, company size, or productive sector, are not determinant. The proposed analysis methodology provides useful indicators for corporate governance bodies to analyze and improve human performance and labor engagement in the face of digitalization, applicable to any type of organization, sector, or country, facilitating the deployment of more economically efficient and socially sustainable transformation programs.
\end{abstract}

Keywords: sustainability strategy; sustainability business; resource management; sustainability indicators; inter- and transdisciplinary sustainability studies; SDGs 2030; non-financial reporting; social sustainability; digital transformation; social taxonomy

\section{Introduction}

The digitalization of companies, as a new mechanization formula, is key to their sustainable competitiveness and, therefore, a source of interest for public policies and scientific literature [1]. The lack of digital skills among the workforce or "digital disability" generated by exponential digitalization has elements in common in the workplace with some forms of disability, such as the ability to lead to loss of employability and, hence, to social exclusion. This paper understands "socially sustainable digital transformation" as that which promotes the labor insertion of workers with "digital disability", through reskilling programs to improve their digital employability.

The concept of sustainability has evolved from that proposed in the Brutland report in 1987 [2], (Brundtland \& Khalid, 1987) to the current three-dimensional concept that includes social, economic and environmental aspects, which should complement each other and consider that economic and social aspects are in fact one and the same [3]. Employee work engagement is a key component of improving the human performance of organizational sustainability by promoting knowledge sharing and innovative work behaviors [4].

Numerous research studies have contributed to the debate on the concept of responsible innovation and its application in the business context, most notably the systematic literature review conducted in 2017 by Rob Lubberink, Vincent Blok, Johan Van Ophem, 
and Onno Omta [5]. The influence of CSR practices on employee attitudes and behaviors and the relationship between CSR practices and organizational performance have also been explored [6]. The influence of leadership style on the sustainability of human capital has also been analyzed [7].

Since the end of the 20th century, there has been much academic research aimed at analyzing the capacity of non-financial indicators to predict the evolution of critical variables, such as profitability or risk or growth capacity, aspects for which financial ratios are particularly weak in their predictive capacity [8]. Non-financial variables are becoming increasingly relevant in audits, purchase processes, sales, or corporate mergers to the point that, on occasions, the expectation of business generation can be valued more highly than foreseeable losses in the short and medium term [9]. In value-based management theories (VBM), the focus was on financial value, but today there is a serious need for valuation and identification of intangible resources related to intellectual capital [10]. It is for this reason and because of the mandate contained in goal 17.19 of the United Nations 2030 Agenda on the need to develop indicators to measure progress in social matters [11], that this research finds an opportunity to advance in the development of material non-financial indicators that correlate the organization's commitment to socially sustainable digital transformation and the improvement of the company's competitive capacity. Within the framework of current norms, standards, and models, consideration is given to the imperative need for progress in social materiality, on which pioneering groups as the Platform on sustainable finance are currently working [12-14].

In the context of the objectives proposed by Directive 2014/95/EU of the European Parliament and of the Council of 22 October 2014 amending Directive 2013/34/EU, and the recent proposal for a Corporate Sustainability Reporting Directive presented by the European Commission in April 2021 as regards disclosure of non-financial information and diversity information by certain large companies and certain groups, this paper aims at a threefold objective: to help define business strategy by improving non-financial information in corporate governance reports to assess more accurately how the company's activities and risks impact on social sustainability; to provide more accurate information to responsible investment funds by assessing the degree of companies' social engagement in the digital divide to anticipate their chances of survival, thus increasing credibility, trust and reputation towards stakeholders; promoting social awareness of the importance of including people in digitalization projects, improving the content of companies' corporate governance reports by incorporating these criteria in the decisions of their management bodies.

\subsection{Theoretical Background}

The methodology proposed in this paper is based on the legal standards for nonfinancial reporting established from the aforementioned Directive 2014/95/EU; the European Commission Communication (2017/C 215/01); the EU Regulation 2019/2075 of 29 November amending certain references to the conceptual framework of the International Financial Reporting Standards (IFRS) contained in Regulation EC No 1126/2008 and clarifies the meaning of the term materiality, which has been reinforced since 2013 by Directive 2013/34/EU on annual financial statements and Directive 2014/95/EU on disclosure of non-financial information and diversity; the Global Reporting Initiative (GRI) standards [15]; the components of the Integrated Reporting Framework Council (IIRC) [16]; codes of good practice on sustainable value creation for capital markets: Principles For Responsible Investment (UN PRI) [17]; International Corporate Governance Network (ICGN) [18]; Global Stewardship Principles [19] and the framework set out in the Investor Stewardship Group (ISG) [20]. Additionally, the IS_IMPACT methodological basis and the study published in 2020 by IESE-Penteo based on a survey on the digital transformation of Spanish companies [21], whose conclusions are cited in the Harvard Deusto journal [22], have also been taken into account. 


\subsection{Challenges for the Implementation of Value-Based Models}

The proposal of this paper is framed within the Value Based Management (VBM) models, with origin in Peter Druker's article "Managing for results; economic tasks and risk-taking decisions" [23], the scope of which has been broadened to offer investors greater security than that offered by financial information alone, as this is not sufficient for correlation with growth and the possibilities of success in an increasingly competitive market [24]. Therefore, further developments of this concept have been taken into account in the works of Copeland, Koller, and Murrin in 1990 Valuation: measuring and managing the value of companies [25]; Norton and Kaplan 1992: The Balanced Scorecard Measures That Drive Performance (Kaplan and Malone 1997) [26]; Intellectual Capital: Realizing Your Company's True Value by Finding Its Hidden Brainpower [27]. Non-financial value can also be reflected in strategic indicators, such as those described by Śledzik [10], compiling the different existing proposals: market capitalization methods (MCM), return on assets methods (ROAM), direct intellectual capital methods (DICM), and scorecard methods (SCM). The latter include methodologies, such as: Balanced Scorecard (BSC), Human Capital Intelligence (HCI), Skandia Navigator ${ }^{\mathrm{TM}}$, Value Chain Scoreboard ${ }^{\mathrm{TM}}$ (VCSTM), ICIndex ${ }^{\mathrm{TM}}$, Business IQ ${ }^{\mathrm{TM}}$, National IC, Holistic Accounts, IC Rating ${ }^{\mathrm{TM}}$, MAGIC, IC-dVAL ${ }^{\mathrm{TM}}$, Danish Guidelines, Meritum guidelines, Intangible Assets Monitor (IAM) [28], Value Creation Index, and Knowledge Audit Cycle.

\subsection{Hypothesis Development. Conceptual Background}

With the final objective of promoting sustainability in its social dimension, it is demonstrated through a system of indicators useful for the different stakeholders, that business investment in programs for the digital reskilling of the workforce has a direct impact on the improvement of the company's competitive capacity based on the following hypotheses:

Hypothesis 1. The proposed non-financial indicators are useful to measure the correlation between the organization's commitment to socially sustainable digital transformation and the improvement of business capabilities. The general synthetic Workforce Digital Transformation Impact Index@ (WDTIIC) is valid as a general measurement tool: the WDTIIC synthetic index proposed in this paper, composed of 18 quantitative variables grouped around 5 business fields, is a consistent and reliable non-financial indicator to measure this purpose. Several hypotheses are set out below on how workforce digital skills development programs impact on each of the 5 business fields for which a specific synthetic indicator is proposed.

Hypothesis 2. There are significant differences in the perception of the business impact generated by the improvement of the digital capabilities of the workforce according to some variables, while others are not determinant.

\subsection{Aim of the Work and Conclusions}

Within the framework of value-based management systems, this study, aimed at decision-making based on the value generated for the different stakeholders, advances in the proposal of material non-financial indicators that correlate the organization's commitment to socially sustainable digital transformation and the improvement of the company's competitive capacity. Six non-financial indicators of digitalization are proposed: an overall synthetic index based on 18 variables, reflecting the perceived impact on the business due to workforce digitalization programs; and five synthetic sub-indices by business field. All this is analyzed according to nine categorical variables: type of organization, company size, sector of activity, number of years that specific digital reskilling programs have been implemented among the workforce, role, organizational area, gender, generation, and cultural zone; an analysis of the results obtained and a specific analysis of the improvement in efficiency and business productivity perceived after COVID-19, as a temporary accelerator of digital transformation, is carried out. 
The adaptation to these objectives of the IS_IMPACT methodology on which this work is based should generate two additional methodological benefits by taking advantage of the opportunity for innovation provided by the lack of literature in this field and the limited availability of tools: to offer a formula for identifying and measuring the contribution of digital training programs for workers to improving business competitiveness, by presenting solid, novel, and useful methodological advances; to evaluate the impacts generated on the potential beneficiary areas in the company in an organized, structured, and quantified way, offering a useful tool for monitoring and evaluating the contribution of these initiatives, beyond the simple measurement of the degree of deployment or adoption of technological infrastructures, being applicable to all types of companies, sectors, and organizations as it is based on a broad and flexible design.

\section{Materials and Methods}

Sustainability researchers can categorize their research to improve the common understanding of the concept across diverse formulations. This research is based on transdisciplinary methodology characterized by synthesizing new disciplines and theory; focusing on solving specific problems on a topic through a coordinated, integrated, and iterative research process, involving multiple disciplines, but above all taking stakeholders into account in the research process; sharing knowledge across disciplines by crossing epistemological boundaries; and following a pluralistic methodology involving the implementation of results as part of the process [29].

The IS_IMPACT methodological framework was created in 2018 for measuring the social inclusion impact of disability employment programs [30]. To assess the company's commitment to inclusive digitalization, we propose adapting this open model, which is relevant to this field of study as it has been successfully tested for measuring the impact in terms of social inclusion of employment programs in the field of disability. To do this, it is necessary to define the components that determine the success of the company as a managing agent for workers with "digital disabilities" and to draw up a scheme that brings them together in a structured way, establishing a series of parameters common to practically all companies.

\subsection{Implementation of the Impact Map}

Programs to improve the employability of workers with a "digital disability" can generate different types of advantages or impacts for the contracting companies in their various business areas. The impact map is structured on two levels. The first is the "business fields": general dimensions consisting of a set of activities of a similar and interrelated nature that are necessary for the achievement of business goals and objectives. The methodology proposes grouping them into five fields sufficiently representative of the different areas of any company: growth (in this study, it is adapted as "business development"), "customers", "operations", "people", and "environment". Some are internal, and others external, extending to investors, suppliers, consumers, and society, in general. Furthermore, "each dimension is autonomous, but not independent of the others, as they all integrate and interact with each other to achieve the objectives pursued by the organizations". The second level are the "business parameters": more concrete and appropriate categories for the articulation of the measurement proposed specifically for the purpose of this work. For the construction of the "impact map", six renowned professionals from the fields of business consultancy, digital transformation and academic research were interviewed between 15 January and 14 March 2021, with knowledge of the stakeholders related to each of the five proposed fields. As a result, the impact of the programs to improve the digital employability of the workforce is defined in a descriptive way, and the opportunity to analyze eighteen business parameters based on which the survey is constructed is determined. 


\subsection{Measures: Operationalization of Digital Orientation}

\subsubsection{General Questionnaire: Development of an Evaluation Guide}

As shown in Table 1, the eighteen quantitative variables called "parameters" are grouped according to the five "business fields". Thus, "business development" includes innovation, prediction, and other actors; "customers": value proposition, accessibility, and customization; "operations": efficiency and quality, security, and value chain; "workforce": satisfaction, work-life balance, diversity, leadership, and culture; "business environment": sustainability, reputation, business opportunities, and investors.

Table 1. Map of business impacts of digital transformation programs on the workforce. Source: own elaboration.

\begin{tabular}{|c|c|c|c|c|c|}
\hline Business Field & $\begin{array}{c}\text { Business } \\
\text { Development }\end{array}$ & Customers & Operations & Workforce & $\begin{array}{c}\text { Business } \\
\text { Environment }\end{array}$ \\
\hline \multirow{4}{*}{$\begin{array}{c}\text { Business } \\
\text { parameters }\end{array}$} & Innovation & Value proposition & Efficiency\& quality & Satisfaction & Sustainability \\
\hline & Prediction & Accessibility & Security & Work-life balance & Reputation \\
\hline & Other actors & Customization & \multirow[t]{2}{*}{ Value chain } & Diversity & $\begin{array}{c}\text { Business } \\
\text { opportunities }\end{array}$ \\
\hline & & & & $\begin{array}{l}\text { Leadership } \\
\text { Culture }\end{array}$ & Investors \\
\hline
\end{tabular}

A general questionnaire with eighteen questions corresponding to the eighteen business parameters is developed to analyze the respondent's perception of the impact of improving the digital skills of the workforce in relation to each of them based on a Likert scale, where " 0 " represents zero impact, " 5 " unknown impact, and " 10 " high impact. It is adjusted with fifteen respondents of different profiles to ensure comprehensibility. In line with corporate reporting trends, this work uses a minimum number of indicators. To understand the overall impact of improving the digital skills of the workforce, an overall synthetic index calculated as an average of the responses corresponding to the eighteen business parameters is proposed, which is called the Workforce Digital Transformation Impact Index@ (WDTIC). Thus, WDTIIC = total sum of the scores divided by (number of respondents $\times 18$ questions). To understand the specific impact of improving the digital skills of the workforce on each of the five business fields, five synthetic sub-indices are proposed, calculated as an average of the business parameters included in each of them. Thus, index per field $=$ total sum of the scores corresponding to each field divided by (number of respondents $\times$ number of questions corresponding to that field). Finally, a specific sub-index is proposed for each of the eighteen parameters calculated as the sum of the scores for each parameter divided by the number of respondents. A separate question of interest to this paper is asked during the pandemic period on the perception of the possible impact on the improvement of the company's efficiency and productivity caused by the acceleration of the digital transformation generated by COVID-19, also quantitative and on a Likert scale.

\subsubsection{Control Variables}

To analyze whether differences are perceived in each respondent segment, self-ratings are requested based on nine categorical variables based on multiple choice answers.

\subsubsection{Participants and Procedure: Data Source and Collection}

To determine the representative sample size of the population under study, a margin of error of $5 \%$, a confidence level of $95 \%$, and a population size of 1,000,000 individuals were considered. A minimum sample size of 384 individuals was determined based on the findings of Torres and Salazar's work [31]. The survey in Appendix A was carried out between 15 March 2021 and 4 April 2021, seeking temporal homogeneity in the results, one year after the start of COVID-19, which had driven a forced acceleration of digital transformation in companies. The survey was set up in Spanish and English on the Typeform online platform; no text fields were open, except for the company name and email. Direct 
messages were sent to 1758 people through the professional network Linkedin and email, selected from a set of recognized international professionals, sufficiently representative of the diverse types of organizations, company sizes, business sectors, number of years of experience in digital transformation programs, roles, business areas, gender, generation, and cultural areas. The survey was closed when 387 valid responses were received from the 40 countries described in Table 2. Once the sample had been collected and the database created in IBM SPSS version 25.0 software, we proceeded to the descriptive analysis of all the variables under study, creating the appropriate tables and graphs depending on the nature of the variable.

Table 2. Control variables. Company size based on the definition accepted by the European Commission; cultural areas, considered according to the Ronald Inglehart and Christian Welzel World Values [32]. Source: own elaboration.

\begin{tabular}{|c|c|c|c|}
\hline Organization & $\begin{array}{l}\text { Size of Your Company } \\
\text { within the Country }\end{array}$ & Business Sector & $\begin{array}{l}\text { Years Running Digital } \\
\text { Training Programs for Staff }\end{array}$ \\
\hline $\begin{array}{l}\text { National } \\
\text { company }\end{array}$ & $\begin{array}{l}\text { Microenterprise } 1-9 \text { workers; } \\
\leq € 2 \mathrm{~mm} \text { business volume }\end{array}$ & $\begin{array}{l}\text { Primary agriculture, livestock, } \\
\text { and fishing }\end{array}$ & There are no specific programs \\
\hline $\begin{array}{l}\text { Multinational } \\
\text { company }\end{array}$ & $\begin{array}{l}\text { Small business } 10-49 \text { workers; } \\
\leq € 10 \text { mm business volume }\end{array}$ & $\begin{array}{l}\text { Secondary artisanal, industrial, } \\
\text { construction, energy, textile, mining, } \\
\text { oil extraction, packaging, bottling }\end{array}$ & $<1$ year \\
\hline \multirow[t]{3}{*}{$\begin{array}{c}\text { Public } \\
\text { administration }\end{array}$} & $\begin{array}{l}\text { Medium company } 50-249 \text { workers; } \\
\leq € 50 \text { mm business volume }\end{array}$ & $\begin{array}{l}\text { Tertiary services, financial, trade, } \\
\text { transport, public administration, } \\
\text { distribution, security, tourism, } \\
\text { (hotels and restaurants), } \\
\text { telecommunications }\end{array}$ & $>1$ and $<3$ \\
\hline & $\begin{array}{l}\text { Large company > } 250 \text { workers; } \\
>€ 50 \text { mm business volume }\end{array}$ & $\begin{array}{l}\text { Quaternary consulting, research, } \\
\text { development, innovation, and } \\
\text { information }\end{array}$ & $>3$ and $<5$ \\
\hline & & $\begin{array}{l}\text { Quinary culture, entertainment, } \\
\text { education, health/hospital }\end{array}$ & 5 or more \\
\hline Current role & Working Area & Cultural area & Generation \\
\hline Director & $\begin{array}{c}\text { Senior Management Senior } \\
\text { Management/Business Owner + } \\
\text { Strategy/Project Management Office }\end{array}$ & $\begin{array}{c}\text { English speaking Canada, United } \\
\text { Kingdom, USA }\end{array}$ & $\begin{array}{l}\text { Baby Boom } \\
(1945-1964)\end{array}$ \\
\hline $\begin{array}{l}\text { Middle } \\
\text { management }\end{array}$ & $\begin{array}{l}\text { Business Development Innovation + } \\
\text { Digital transformation }\end{array}$ & $\begin{array}{l}\text { Catholic Europe Belgium, Spain, } \\
\text { Lithuania, }\end{array}$ & $\begin{array}{l}\text { Generation X } \\
(1965-1981)\end{array}$ \\
\hline \multirow[t]{6}{*}{$\begin{array}{l}\text { Not in charge of } \\
\text { a team }\end{array}$} & $\begin{array}{c}\text { Customers } \\
\text { Commercial/Marketing/Business } \\
\text { Development }\end{array}$ & $\begin{array}{l}\text { Protestant Europe Germany, } \\
\text { Sweden, Switzerland }\end{array}$ & $\begin{array}{l}\text { Generation } \\
\text { Y/millennial } \\
(1982-1994)\end{array}$ \\
\hline & $\begin{array}{l}\text { Operations Operations/Technical + } \\
\text { Technology and Processes + Security }\end{array}$ & Orthodox Europe Greece, Russia & $\begin{array}{l}\text { Generation } \\
\text { Z/centennial } \\
(1995-2010)\end{array}$ \\
\hline & Workforce Human Resources/Talent & $\begin{array}{l}\text { African Islamic Algeria, Bahrein, } \\
\text { Dubai, Egypt, India, Indonesia, } \\
\text { Jordan, Kuwait, Morocco, Oman, } \\
\text { Saudi Arabia, Tunisia, Turkey }\end{array}$ & \\
\hline & $\begin{array}{l}\text { Business Environment Corporate } \\
\text { Social Responsibility/Sustainability } \\
\text { + Financial/Administrative/ } \\
\text { Investments + Internal Audit + } \\
\text { Communication }\end{array}$ & $\begin{array}{c}\text { Latin America Argentina, Brazil, } \\
\text { Colombia, Costa Rica, Ecuador, El } \\
\text { Salvador, Mexico, Panama, Uruguay, } \\
\text { Venezuela }\end{array}$ & \\
\hline & & $\begin{array}{c}\text { West \& South Asia Chile, Israel } \\
\text { South Africa }\end{array}$ & \\
\hline & & Confucian China, Hong Kong, Japan & \\
\hline
\end{tabular}




\subsubsection{Data Analysis}

- Consistency analysis. A reliability analysis of the Workforce Digital Transformation Impact Index@ (WDTIIC) was carried out to measure its internal consistency, based on Cronbach's alpha method [33]. This index, composed of 18 items measured on a Likert-type scale obtained a value of 0.924 , which reflects an excellent reliability and a high correlation of its elements as an instrument to measure its purpose [34]. As seen in Table 3, each one of the parameters reflected a value above 0.918 so that each question in the questionnaire also reflects excellent reliability: the cancellation of any of the questions generates a drop in value for the overall index, which implies that each of them adds value for the purpose measured. We proceeded to test the objectives by applying hypothesis testing, previously verifying that the assumptions were fulfilled to be applicable.

Table 3. Reliability analysis of the Workforce Digital Transformation Impact Index@ (WDTIIC) based on Cronbach's alpha. Source: own elaboration.

\begin{tabular}{|c|c|c|c|c|}
\hline $\begin{array}{l}\text { Business } \\
\text { Parameter }\end{array}$ & $\begin{array}{l}\text { Scale Mean If } \\
\text { Item Deleted }\end{array}$ & $\begin{array}{l}\text { Scale Variance } \\
\text { If Item Deleted }\end{array}$ & $\begin{array}{l}\text { Corrected } \\
\text { Item-Total } \\
\text { Correlation }\end{array}$ & $\begin{array}{l}\text { Cronbach's } \\
\text { Alpha If Item } \\
\text { Deleted }\end{array}$ \\
\hline Innovation & 12,154 & 562,581 & 0522 & 0922 \\
\hline Prediction & 12,274 & 532,138 & 058 & 0921 \\
\hline Other actors & 12,231 & 542,484 & 0616 & 0919 \\
\hline $\begin{array}{c}\text { Value } \\
\text { proposition }\end{array}$ & 12,191 & 54,844 & 0617 & 0919 \\
\hline Accessibility & 12,083 & 567,429 & 0464 & 0923 \\
\hline Customization & 12,224 & 545,259 & 0637 & 0919 \\
\hline $\begin{array}{c}\text { Efficiency \& } \\
\text { quality }\end{array}$ & 12,155 & 560,912 & 0566 & 0921 \\
\hline Security & 12,247 & 546,954 & 0578 & 092 \\
\hline Value chain & 12,239 & 546,472 & 063 & 0919 \\
\hline Satisfaction & 12,252 & 534,214 & 0664 & 0918 \\
\hline $\begin{array}{l}\text { Work-life } \\
\text { balance }\end{array}$ & 12,225 & 549,827 & 0468 & 0923 \\
\hline Diversity & 12,239 & 539,569 & 0706 & 0917 \\
\hline Leadership & 12,309 & 530,332 & 0702 & 0917 \\
\hline Culture & 12,253 & 539,234 & 0701 & 0918 \\
\hline Sustainability & 12,307 & 528,513 & 0689 & 0918 \\
\hline Reputation & 1221 & 543,294 & 0652 & 0919 \\
\hline $\begin{array}{c}\text { Business } \\
\text { opportunities }\end{array}$ & 12,304 & 533,395 & 0608 & 092 \\
\hline Investors & 12,292 & 529,325 & 0627 & 0919 \\
\hline
\end{tabular}

- Descriptive analysis. A descriptive analysis is carried out for the main quantitative variables: general index, business fields, and business parameters, as well as for the COVID-19 question. When the number of responses is greater than 50 , the Kolmogorov-Smirnov normality test is performed [35]. This is the case for the general Workforce Digital Transformation Impact Index@ (WDTIIC), the 5 synthetic indices, the 18 parameters, and the question on COVID-19, all of which had 387 responses. Given that the $p$-value of the normality test is significant $(p<0.05$ or sig. $<0.05)$ for all quantitative variables, the hypothesis that none of them has a normal distribution is accepted, so non-parametric tests are applied for hypothesis testing. In those cases where the number of responses is less than 50 , which occurs for some specific items of the categorical variables, the Shapiro-Wilk test is applied [36,37]. If $p<0.05$, the hypothesis that the variable does not have a normal distribution is accepted, while, if $p>0.05$, the hypothesis that it does have a normal distribution is accepted.

- Hypothesis contrast. Tests of independence are performed to check whether the quantitative variables (Likert-scale responses) are independent with respect to the 
control variables (categorical) used as factors. That is, the means of the distributions of the quantitative variables in the different groups established by the qualitative or categorical segmentation variables are compared using different tests of independence: if the quantitative variable is normally distributed in the different categories of the qualitative variable, parametric tests are used. When the categorical variable has 2 categories, the Student's $t$-test is used [38]; if it has 3 or more categories, the comparison of means is carried out through the analysis of variance Anova a situation that has not occurred in this study [39]; if the quantitative variable does not have a normal distribution in the different categories of the qualitative variable, non-parametric tests are used: when the categorical variable has 2 categories, the Mann-Whitney $U$ test is used [40,41]; if there are 3 or more groups, the Kruskal-Wallis test is used [42].

- Correlation analysis. Correlation tests are applied to measure the degree of association between two quantitative variables, focusing the study on the relationship called linear and considering only two (simple) variables. When the distribution of both variables is normal, Pearson's correlation is used [43]. Otherwise, Spearman's correlation is used [44].

\section{Results}

\subsection{Descriptive Statistics}

As shown in Table 4, the greatest perceived impact of digital transformation programs for the workforce is on the business field "customers", and the least on the "business environment". As shown in Table 5, the greatest impact of these programs is perceived in the improvement of accessibility from any place, device or channel at any time; innovation in channels, sectors, markets, products or services, simplifying them or improving the product mix; the improvement of efficiency and quality in processes through the applied use of technology with a mean of almost 8 in the responses, while the least impact is perceived in this order in the promotion of leadership by objectives based on trust, transparency, and closeness of employees, the promotion of decision-making by teams and the delegation of a certain level of risk; the improvement of their Corporate Social Responsibility and Social Sustainability; and the generation of new business opportunities with public administrations or large companies and the improvement of the attractiveness of the company for investors.

Table 4. Impact of digital transformation programs on the workforce, per business field. General descriptive analysis of the 5 quantitative variables "synthetic indicators by fields" and "WDTII@ general synthetic indicator". Source: own elaboration.

\begin{tabular}{ccccccc}
\hline & $\begin{array}{c}\text { Business } \\
\text { Development }\end{array}$ & Customers & Operations & Workforce & $\begin{array}{c}\text { Business } \\
\text { Environment }\end{array}$ & $\begin{array}{c}\text { Workforce Digitalization } \\
\text { Impact Index@ }\end{array}$ \\
\hline $\begin{array}{c}\text { Mean } \\
\begin{array}{c}\text { Std. } \\
\text { Deviation }\end{array}\end{array}$ & 7327 & 7861 & 7387 & 6966 & 6741 & 7196 \\
\hline
\end{tabular}

Table 5. Impact of digital transformation programs on the workforce, per business parameter. General descriptive analysis of the 18 quantitative variables "parameters". Source: own elaboration.

\begin{tabular}{|c|c|c|c|c|c|c|c|c|c|}
\hline & Innovation & Prediction & $\begin{array}{l}\text { Other } \\
\text { Actors }\end{array}$ & $\begin{array}{c}\text { Value } \\
\text { Proposition }\end{array}$ & Accessibility & Customization & $\begin{array}{l}\text { Efficiency } \\
\text { \& Quality }\end{array}$ & Security & $\begin{array}{l}\text { Value } \\
\text { Chain }\end{array}$ \\
\hline \multirow{3}{*}{$\begin{array}{c}\text { Mean } \\
\text { Std. } \\
\text { Deviation }\end{array}$} & 7984 & 6786 & 7212 & 7612 & 8687 & 7284 & 7974 & 7057 & 7129 \\
\hline & 1660 & 2537 & 2079 & 1885 & 1642 & 1931 & 1601 & 2044 & 1911 \\
\hline & Satisfaction & $\begin{array}{c}\text { Work-life } \\
\text { balance }\end{array}$ & Diversity & Leadership & Culture & Sustainability & Reputation & $\begin{array}{l}\text { Business op- } \\
\text { portunities }\end{array}$ & Investors \\
\hline \multirow{2}{*}{$\begin{array}{l}\text { Mean } \\
\text { Std. De- } \\
\text { viation }\end{array}$} & 7003 & 7269 & 7137 & 6437 & 6987 & 6450 & 7426 & 6483 & 6605 \\
\hline & 2195 & 2332 & 1926 & 2203 & 1948 & 2293 & 1952 & 2396 & 2463 \\
\hline
\end{tabular}


The question on the impact of COVID-19 has a mean of 7.70 and a standard deviation of 1.989 .

\subsection{Multilevel Analysis}

After descriptive and exploratory analyses of the responses, statistically significant differences are analyzed according to the categorical variables.

\subsubsection{Company Type}

In domestic companies, there is a lower perception of the impact of business investment in programs for the digital reskilling of the workforce on the operational environment than in multinationals, specifically in the parameters relating to "improving security in the face of new risks and limiting the impact of the unpredictable, thanks to technology" and "improving collaboration with suppliers to generate some advantage in the value chain".

Based on the Kruskal-Wallis test, the hypothesis that there is only significant difference between "domestic companies", "multinational companies", and "public administration" in the business fields "business development" $(p=0.017)$ and "operations" $(p=0.010)$ is accepted with 95\% confidence. After performing Mann-Whitney pairwise tests to observe between which company typology there was such a difference, significance was found in the "operations" field between "national companies" and "multinational companies" $(p=0.007)$, with the parameters showing significant differences being "security" $(p=0.034)$ and "value chain" $(p=0.012)$. This finding suggests that improving the digital capabilities of the workforce allows multinational companies to find greater efficiencies than domestic firms in operations, security, and vertical integration with suppliers, possibly due to the opportunity to attract and develop talent with more diverse and enriching experiences across cultural backgrounds. The greatest opportunities for improving digitalization possibilities are seen in public administrations. This is deduced after performing Mann-Whitney pairwise tests to observe between which company typology there was such a difference. Significance was found in "business development" between "public administration" and "national companies" ( $p=0.022)$ and between "public administration" and "multinational companies" ( $p=0.007)$.

This finding could be due to the lack of competition and demand from "owners" and "environment". It could be argued that the public status makes it difficult to generate the impact of digitalization of the workforce across the board, while the multinational status favors it.

3.2.2. Number of Years That Specific Digital Skills Programs Have Been Running among the Workforce

Companies that have been running specific programs of digital reskilling of the workforce for between one and three years have a lower perception of their impact on the company than companies that have been running specific programs for less than one or more than three years. The first business fields to perceive the impact of these programs are "workforce", in particular, the "satisfaction of employees feeling that the company is committed to their employability"; the "generation of synergies between teams with different levels of digital skills and business knowledge, developing a transparent, close, goal-based leadership, favoring decision-making by the teams, delegating a certain level of risk"; and the "promotion of a business culture based on the open exchange of knowledge, more conducive to obtaining competitive advantages". In addition, the "environment" business field, in particular, the "improvement of Corporate Social Responsibility and Social Sustainability of the company"; the "improvement of reputation and brand image"; and the "improvement of the attractiveness of the company for investors".

On the other hand, the last business fields where the impact of these programs is perceived are "customers", particularly the "improvement of the agility and elasticity of the company's value proposition to their changing needs"; the "improvement of their accessibility from any place, device, or channel and at any time"; and the "improvement of their retention through customization, relationship management, feedback management 
(communities, social networks, etc.), cross-selling, loyalty programs, etc.", as well as the field of "operations" and, in particular, the "improvement of efficiency and quality in processes through the applied use of technology"; and the "improvement of collaboration with suppliers to generate some advantage in the value chain". Based on the KruskalWallis test, the hypothesis that the differences are significant in the overall WDTIIC index and all business fields obtain a $p=0.000$ is accepted with $95 \%$ confidence.

After performing the Mann-Whitney pairwise tests to observe between which groups, in particular, this difference occurs according to the number of years of development of these programs, significance was obtained in the variable "number of years that specific digital reskilling programs have been implemented among the workforce" between "no years" vs. "1-3, 3-5" and " $>5$ " by obtaining $p$-values of less than 0.05 in all fields and in the general index. In the case of the comparisons: "1-3" vs. "3-5" significant differences are observed for the "workforce" and "environment" fields, as well as for the general WDTIIC index; "1-3" vs. ">5" significant differences are observed for the "customers", "operations", "workforce", and "environment" fields, as well as for the general WDTIIC index. For the variable "years of development of digitalization programs", all parameters show significant differences except "security" (field "operations"), "reconciliation" (field "workforce"), and "business opportunities" (field "environment").

This finding suggests that there is a rapid perception of impact during the first year, which stagnates and even decreases between the first and third year, increasing again from the third year onwards in all business fields and in the overall WDTIIC index. This phase of resistance, commonly known in change management techniques as the "valley of despair", is usually caused by the awareness of imminent change, the abandonment of the "comfort zone" and "status quo", when instability is perceived, doubts about one's own ability to perform the job under the new way of doing things and fear for survival in the job, which leads to loss of motivation and possibly loss of productivity that could be mitigated in the interest of the different stakeholders through specific change management techniques based on effective communication.

The parameters that are most quickly permeable to these programs are probably the most difficult to translate into turnover. Thus, staff satisfaction and the perception of making the most of their diversity, improved leadership and a culture more open to knowledge sharing, together with improved corporate social responsibility, reputation and brand image, and attractiveness to investors. In contrast, the perception of impact takes longer to occur on those parameters more directly linked to the income statement, such as improved value proposition and customer accessibility, customer retention through a customized offer, improved efficiency and quality in operations, and collaboration with suppliers. All this suggests that staff digitalization programs require time to mature, beginning to be perceived in "soft" parameters, while, in the "hard" ones, more directly linked to the profit and loss account, are perceived from the third year after their implementation.

\subsubsection{Job Level}

"Middle managers" perceive a greater impact from improving the digital skills of the workforce than "managers" and "non-managers", particularly in the "customers" field and more specifically in "improving customer retention through customization, relationship management, feedback management (communities, social networks, etc.), cross-selling, loyalty programs, etc.". Based on the Kruskal-Wallis test, the hypothesis that differences are significant only in the business field of "customers" is accepted with $95 \%$ confidence $(p=0.026)$. After performing Mann-Whitney pairwise tests to observe between which job levels there was such a difference, significance was obtained for the variable "job level" between "middle management" and "director" $(p=0.019)$, and between "middle management" and "non-managerial staff" $(p=0.033)$. The parameters that show significant differences are "improving retention by customization, relationship management, feedback management (communities, social networks, etc.), cross-selling, loyalty programs, etc." 
This finding suggests that, following their participation in digital transformation programs, middle managers perceive their ability to have the greatest impact on those aspects related to personalizing the customer relationship and managing customer feedback. The lack of perceived differences in impact on any specific field by managers is possibly due to their overall view of the strategy and effects of digital transformation, with a balanced perception of impact on different fields; this same circumstance among non-managerial staff suggests an opportunity for improvement in communicating about the purpose and effects of digitalization, assuming that they do not have as much natural visibility of its impact on fields, such as "environment" and "business development".

\subsubsection{Area of Work}

The HR area perceives the greatest impact of the improvement of workers' digital skills on the business field "workforce". In particular, this is on the "increase in employee satisfaction as they feel that the company is committed to their employability", and on the "generation of synergies between teams with different levels of digital skills and knowledge of the business". Based on the Kruskal-Wallis test, the hypothesis that the differences are significant only in the business field "workforce" $(p=0.014)$ and in the overall WDTII $\odot$ index $(p=0.015)$ is accepted with $95 \%$ confidence. After performing Mann-Whitney pairwise tests to observe between which work areas this difference occurs, statistical significance was obtained in the appreciation of the impact of these programs in the business field "workforce" between the areas of "HR" vs. "senior management" $(p=0.007) ;$ "HR" vs. "customers" $(p=0.025) ;$ "HR" vs. "operations" ( $p=0.031) ;$ "HR" vs. "others" $(p=0.000)$. For the variable "work area", the parameters with significant differences are "security" $(p=0.009)$, "satisfaction" $(p=0.001)$, "diversity" $(p=0.022)$, "sustainability" ( $p=0.037)$, and "investors" ( $p=0.025)$.

This finding suggests that the HR area is the one that has the greatest perception of impact on those aspects specifically related to its own area, with no other area perceiving an impact on its own natural parameters. This fact could be related to the observation made above that the first business fields to perceive the impact of these programs are those related to people management, which allows HR to be the area with the longest time span in the perception of these impacts; it could also be due to the fact that the management of the digital transformation change associated with people is usually the responsibility of this area and also because it is possibly the area that most easily establishes a link between the digital reskilling of the workforce and its results, with the impacts on other business parameters associated with the income statement being subject to a large number of interrelated variables. This suggests an opportunity for improvement in communicating the purposes and results of these programs to all areas of the business.

\subsubsection{Cultural Area}

It is worth noting the lower impact of business investment in programs for the digital reskilling on the "workforce" business field in the "Protestant Europe" cultural area (Germany, Sweden, and Switzerland) compared to "English-speaking" (United Kingdom, USA, Canada), "Catholic Europe" (Spain, Belgium, Lithuania), "Latin America" (Argentina, Uruguay, Ecuador, Venezuela, Colombia, Costa Rica, El Salvador, Panama, Mexico, and Brazil), and "Others". In particular, this is on the "optimization of the use of their time by improving their work-life balance and by developing transparent, close, objective-based leadership, which favors decision-making by the teams, delegating a certain level of risk". It also highlights the lower impact of these programs on the business field "operations" by the cultural area "Protestant Europe" compared to "Catholic Europe", "Latin America", and "Islamic Africa" (Turkey, Oman, Saudi Arabia, Egypt, Tunisia, Dubai, Kuwait, Bahrain, Jordan, Algeria, Morocco, India, and Indonesia). In particular, this is on the "improvement of efficiency and quality in processes through the applied use of technology". It also highlights the appreciation of the greater impact of these programs on business "operations" by the cultural area "Islamic Africa" vs. "English-speaking" and "Catholic Europe". In 
particular, this is on the "improvement of efficiency and quality in processes through the applied use of technology". Based on the Kruskal-Wallis test, the hypothesis that there are significant differences in the fields of "operations" $(p=0.049)$ and "workforce" $(p=0.029)$ is accepted with 95\% confidence. After performing Mann-Whitney pairwise tests to observe between which particular cultural areas such a difference occurs, statistical significance was obtained in the assessment of impact on the fields of "operations" and "workforce" between the following cultural areas: "Protestant Europe" vs. "English-speaking" in the business field "workforce" ( $p=0.012)$; "Protestant Europe" vs. "Catholic Europe" in the business fields "operations" $(p=0.019)$ and "workforce" $(p=0.002)$; "Protestant Europe" vs. "Islamic Africa" in the business field "operations" ( $p=0.005)$; "Protestant Europe" vs. "Latin America" in the business fields "operations" ( $p$ 0.025) and "workforce" $(p=0.000)$; "Protestant Europe" vs. "other" in the business field "workforce" ( $p=0.010)$; "Islamic Africa" vs. "English-speaking" in the business field "operations" ( $p=0.046)$; "Islamic Africa" vs. "Catholic Europe" in the business field "operations" ( $p=0.043)$. Significantly different parameters are innovation $(p=0.014)$, other stakeholders $(p=0.036)$, efficiency and quality $(p=0.022)$, work-life balance $(p=0.031)$, and leadership $(p=0.037)$.

This finding suggests that the "Protestant Europe" area is the one that has reached the highest level of maturity in these programs, which would generate a perception of business normality in the incorporation of these digital capabilities and their effects on their "business as usual". This would be deduced from their lower perception of the impact on improving the work-life balance of their workforces and leadership formulas in line with the digital transformation, which, as we have seen, are two of the first parameters whose impact is recognized after this type of program, compared to "English-speaking", "Catholic Europe", "Latin America", and "other" countries; moreover, because of its lower perceived impact on the achievement of operational efficiencies and quality, as we have seen, it is one of the last business parameters whose impact is perceived after this type of program, compared to "Catholic Europe", "Latin America", and "Islamic Africa". On the contrary, the "African-Islamic" area would have the most room for improvement in achieving operational efficiencies and quality resulting from employee empowerment programs, as we have seen, one of the last business parameters whose impact is perceived after such programs, in comparison to the "English-speaking" and "Catholic Europe" areas.

\subsubsection{Impact of COVID-19}

On the question "Has the acceleration of digitalization generated by COVID-19 had an impact on improving the efficiency and ultimately the productivity of the company?", based on the Kruskal-Wallis test, the hypothesis is accepted with $95 \%$ confidence that there is only a significant difference in the lowest perceived impact on the business field "business development". In particular, "innovation in channels, sectors, markets, products, or services, simplifying them or improving the product mix", "use of data or artificial intelligence to predict customer behavior", and "improved coordination with other business actors, such as digital ecosystems or new B2B2C platforms". Based on the tests of independence, the hypothesis that there is a significant difference depending on the area of work can be accepted with $95 \%$ confidence $(p=0.005)$. To see between which types of organizations there is such a significant difference, pairwise tests are performed, in this case the non-parametric Mann-Whitney test. We found a significant difference between: "business development" vs. "top management" ( $p=0.015)$; "business development" vs. "customers" ( $p=0.004)$; "business development" vs. "operations" ( $p=0.033)$; "business development" vs. "other" $(p=0.001)$.

This finding suggests that, although COVID-19 has been an accelerator of digitalization processes, no specific impact has been perceived on innovation in channels, sectors, markets, products, or services, simplifying them or improving the product mix. Nor in the use of data or artificial intelligence to predict customer behavior or in improving coordination with other business actors, such as digital ecosystems or new B2B2C platforms. 


\subsubsection{Other Variables}

Based on the Kruskal-Wallis test, the hypothesis is accepted with $95 \%$ confidence that there are no significant differences in the perception of the impact of business investment in programs for the digital reskilling of the workforce according to the variables: "size of the company in the country", "sector in which the company operates", "gender", or "generation" of the person interviewed in relation to any parameter, business field or the general WDTII $\odot$ index, when testing for independence that $p>0.05$ in all cases.

This finding shows that the perceived impact of improving the digital skills of the workforce does not vary according to objective characteristics of the company, such as size or sector of activity, or of the respondent, such as gender or age.

\subsubsection{Correlation}

There is a slightly higher correlation coefficient for the business fields "workforce" (0.872) and "environment" (0.863) with the general WDTII@ index, these two having the greatest influence on it as they contain 5 and 4 parameters, respectively, while the three remaining fields "business development" (0.727), "clients" (0.743), and "operations" (0.767) contain 3.

\section{Conclusions and Discussion}

This study conceptualizes and articulates the business impact analysis of digital transformation programs for employees. It introduces a novel non-financial strategic indicator on social sustainability based on five business fields and eighteen interrelated parameters, based on stakeholder interests. It operationalizes the concept for further analysis and validates the measurement instrument. It analyzes the key factors in the deployment of these programs through research conducted in 40 countries. It demonstrates that corporate commitment to socially sustainable digitalization improves business performance.

\subsection{Theoretical Implication Contribution}

Despite the necessity and advantages of their formulation, the execution of valuebased management systems has encountered common difficulties in their implementation described by various authors: incomplete linkage of realities between capital markets and company fundamentals; dissociation between corporate culture and benefits of VBM systems due to conflicting rules that prevent focusing on long-term objectives; lack of harmonization with planning, budgeting, and incentive systems [45]; if the rules that create value in their daily work are not understood, employees will not change their behavior and, therefore, do not improve the company's results; difficulty to integrate VBM with other management processes due to lack of non-financial information; excessive focus on financial measures makes efforts to connect these drivers to decisions insufficient [46]; the various formulas and methods of VBM complicate its implementation; complications associated with the use of these metrics; practical difficulty in measuring categories, such as cost of capital; the assessment of factors that can lead to the destruction of shareholder value requires a cautious approach; the implementation of a VBM requires strong and decisive support from the Management Committee; consulting services for the implementation of these systems are costly; there is no ideal model of company valuation as there is no ideal model of VBM since weaknesses and problems are always found [10]. As Śledzik concludes in his research, although most of the existing methods of intellectual capital valuation are difficult to apply, either because they require too much information or are not fully described or because not being numerical they only provide a benchmark, what does not change is the fact that, in the process of creating shareholder value in the knowledge economy and in highly volatile environments, the omission of non-financial value drivers to different stakeholders would be a serious mistake to whose avoidance this work contributes. 


\subsection{Practical Implication}

If getting the formulation of the digital transformation right is the cornerstone of business survival in the face of this new industrial revolution, the search for indicators to measure the success of its implementation in the workforce is a major objective for organizations.

In business practice, there are two ways of constructing the digital transformation scorecard: bottom-up, from the potential of operational advantages towards strategic goals; or top-down, from the strategic vision towards adjustments in the new work formulas, understood as a means to achieve these goals. The first formula has its origin in the production of data, often distorting because it is excessive, usually proposed by the manufacturers of digital software, very tempting at the outset because of its objectivity and visual capacity to create indicators that measure processes in real time that were not previously measured. These are usually instrumental indicators based on operational and tactical data on the degree of adoption of technological tools; digital knowledge or use of agile methodologies by the workforce; or prediction of behavior based on cross-checking data. However, they often lack an a priori strategic approach that justifies both the adoption of these technologies and the indicators themselves, as they do not answer the strategic questions about the real impact on the business in the medium and long term that will determine the chances of business survival. They do not even answer tactical questions, such as how to increase real productivity in order to increase competitiveness based on the time freed up; whether the increase in worker productivity is based solely on the availability of technological tools without considering the impact of motivational factors, such as their willingness to take advantage of them, a temptation of previous industrial revolutions; whether the mere reduction of command structures correlates in itself with greater agility in decision making without taking into account the quality of leadership or corporate culture in key aspects, such as delegation in decision-making; or whether employee satisfaction can be directly correlated with customer satisfaction without taking into account the diversity of impacts that can influence it, such as decisions on areas of the marketing mix in favor or against the immediate interest of the customer, the macroeconomic environment, or the occurrence of unforeseen events.

Today, we have an exponential capacity to measure and generate data, but its consideration should be based on an a priori proposal on its strategic potential impact on the business, based on the traditional scientific method to, if necessary, modify the hypothesis and generate new action plans that add value to the business. The costs of not doing so are large investments without a clear profit horizon, but, above all, an opportunity for decision-makers and stakeholders around the company to be open to future proposals. Either we manage to demonstrate the usefulness in terms of business impact, combining progress with sustainability, or we will exhaust the purpose of the decision-making bodies of companies to take these aspects into consideration. Knowledge capital is not just a metric of the new economy but indicates historical and anticipated profitability over and above the expected rate of return on physical and financial assets, enabling companies to trade at huge multiples over book value [47].

Even with its strengths and weaknesses, the methodology described in this study can be used for several purposes. First, the determination of the ambition of different stakeholders for investments in digital workforce enablement, in terms of business impact. Secondly, the mapping into business parameters and fields to provide managers with a map of the specific aspects they need to analyze to benefit from a socially sustainable digital transformation. The interdependence of these parameters and their strategic value warns against purely operational digital transformation efforts, encouraged by the infinite measurability offered by technology. Third, the results of their execution offer clues to the most decisive categorical factors in implementation. 


\subsection{Limitation and Avenues for Future Research}

Despite its contributions, this study has its limitations. First, following the IS_IMPACT methodology, this work has opted to objectively quantify the global impact of each parameter, starting from the same weight for all of them in the construction of the different synthetic indices proposed by this work. The aim is to gain simplicity in the construction, robustness in the result by avoiding subjectivity in the weighting and to serve as a first approximation. Future research is asked to empirically analyze the possible weighting of the different parameters and fields in the construction of the proposed indices. Second, although an empirical correlation is established between workers' digital skills and business performance, future research should address other specific mechanisms by which such investments lead to performance improvements. For example, a company that invests in the digital skills of its workforce may end up adapting its business model to capture more value from its workers' offerings. Further research is also needed on the correlation between investments in digital skills and other outcomes for the company, such as innovation, new products or services, and customer satisfaction, regardless of employee perceptions [48]. Finally, the concepts assigned to each parameter and business field should be considered revisable over time as the transformation itself evolves. Future research should readjust them through interviews with knowledgeable stakeholders to adapt the digital orientation according to changes in the industry and the market.

To conclude, this study proposes a set of non-financial indicators, conceptualizing and articulating a reliable alternative for measuring the business impact of digital employee empowerment. Within the framework of value-based management theories, legal standards for non-financial reporting and existing methodologies in the market, this study advances research on information systems and strategy. It proposes a strategic concept of digital transformation as a driver of social sustainability based on the ambition of different stakeholders, linking their business interest with the promotion of digital employability of the workforce and measuring the correlation between the two by means of a single indicator. This study suggests that developing the digital skills of the workforce improves business performance in different strategic areas and contributes to preventing the loss of employability and, ultimately, the social exclusion of employees. It is hoped that the proposed concept and methodology will provide a basis for future research to advance the promotion of social sustainability and its management indicators.

\subsection{Patents}

The general synthetic Workforce Digital Transformation Impact Index@ (WDTIIC), composed of 18 quantitative variables grouped around 5 business fields, has been registered as a consistent and reliable non-financial indicator that correlate the organization's commitment to socially sustainable digital transformation and the improvement of the company's competitive capacity.

Author Contributions: A.G.M. and R.J.P.Z. have contributed equally to conceptualization, methodology, validation, formal analysis, investigation, resources, data curation, writing-original draft preparation, writing - review and editing, visualization, supervision, project administration. All authors have read and agreed to the published version of the manuscript.

Funding: This research received no external funding.

Institutional Review Board Statement: Ethical review and approval was waived for this study because it is not a medical research study and it is impossible to identify individuals. This is a non-interventionist study as it is based on an anonymous social media research questionnaire in which all participants were fully informed about their guarantee of anonymity and the exclusively statistical treatment of the data by means of aggregated results from the information obtained, the only way to link a participant with a response being their voluntary cession of an e-mail address in the form in case they wanted to receive the link to the final published manuscript, the e-mail address being equally anonymous. 
Informed Consent Statement: The patient's consent was waived for this study because it is not a medical research study and it is impossible to identify individuals. This is a non-interventionist study as it is based on an anonymous social media research questionnaire in which all participants were fully informed about their guarantee of anonymity and the exclusively statistical treatment of the data by means of aggregated results from the information obtained, the only way to link a participant with a response being their voluntary cession of an e-mail address in the form in case they wanted to receive the link to the final published manuscript, the e-mail address being equally anonymous.

Data Availability Statement: The data presented in this study are available on request from the corresponding authors.

Acknowledgments: The authors wish to acknowledge the three anonymous reviewers for their contribution to the improvement of this manuscript.

Conflicts of Interest: The authors declare no conflict of interest.

\section{Appendix A. Survey}

The following statements are about discovering the actual competitive advantages that the improvement of the digital capabilities of the workforce generates in the business. If you don't know an answer, please rate 5.

Has the improvement of the digital capabilities of the workforce had an impact on business development in your company:

1. by generating innovation in channels, sectors, markets, products or services, simplifying them or improving the product mix?

2. by improving the use of data or artificial intelligence to predict customer behaviour?

3. by improving coordination with other business actors, such as digital ecosystems or new B2B2C platforms?

Has the improvement of the digital capabilities of the workforce had an impact on customers:

4. by improving the agility and elasticity of the company's value proposition in the face of their changing needs?

5. by improving their accessibility from any place, device or channel at any time?

6. by improving their retention through customization, relationship management, feedback management (communities, social networks), cross-selling, loyalty programs, etc.?

Has the improvement of the digital capabilities of the workforce impacted on operations in your company by:

7. gaining efficiency and quality in processes through the applied use of technology?

8. improving security against new risks and limiting the impact of the unpredictable thanks to technology?

9. improving collaboration with suppliers or providers to generate an advantage in the value chain?

Has the improvement of the digital capabilities of the workforce had an impact on the employees:

10. by increasing their satisfaction as they feel that the company is committed to their employability?

11. by optimizing the use of time by improving their work-life balance?

12. by generating synergies between teams with diverse levels of digital training and business knowledge?

13. promoting a goal-based leadership based in employee trust, transparency and closeness, promoting decision-making by teams and delegating a certain level of risk?

14. promoting a business culture based on the open exchange of knowledge, more conducive to obtaining competitive advantages?

Has the improvement of the digital capabilities of the workforce impacted on the business environment of the company in: 
15. improving its Corporate Social Responsibility and Social Sustainability?

16. improving its reputation and brand image?

17. generating new business opportunities with public administrations or large companies?

18. improving the attractiveness of the company for investors? Items measured on a 10-point scale ranging from "zero impact" to "high impact".

\section{References}

1. Liao, Y.; Loures, E.R.; Deschamps, F.; Brezinski, G.; Venâncio, A. The impact of the fourth industrial revolution: A crosscountry/region comparison. Production 2018, 28, e20180061. [CrossRef]

2. Brundtland, G.H.; Khalid, M. Our Common Future; Oxford University Press: Oxford, UK, 1987.

3. Kuhlman, T.; John, F. What is sustainability? Sustainability 2010, 2, 3436-3448. [CrossRef]

4. Kim, W.; Park, J. Examining structural relationships between work engagement, organizational procedural justice, knowledge sharing, and innovative work behavior for sustainable organizations. Sustainability 2017, 9, 205. [CrossRef]

5. Lubberink, R.; Blok, V.; Van Ophem, J.; Omta, O. Lessons for responsible innovation in the business context: A systematic literature review of responsible, social and sustainable innovation practices. Sustainability 2017, 9, 721. [CrossRef]

6. Choi, Y.; Yu, Y. The influence of perceived corporate sustainability practices on employees and organizational performance. Sustainability 2014, 6, 348-364. [CrossRef]

7. Di Fabio, A.; Peiró, J.M. Human capital sustainability leadership to promote sustainable development and healthy organizations: A new scale. Sustainability 2018, 10, 2413. [CrossRef]

8. Laitinen, E.K. Nonfinancial factors as predictors of value creation: Finnish evidence. Rev. Account. Financ. 2004, 3, 84. [CrossRef]

9. Lammers, T. Non-Financial Factors that Affect the Value of Your Business. Business.com. 18 September 2019. Available online: https:/ / www.business.com/articles/value-of-your-business/ (accessed on 24 October 2021).

10. Śledzik, K. Financial and Non-Financial Value Drivers in Shareholder Value Creation Process; Hittmar, S., Ed.; Young Scientists Revue, Faculty of Management Science and Informatics; University of Zilina: Žilina, Slovakia, 2013. Available online: https: / / papers.ssrn.com/sol3/papers.cfm?abstract_id=2257767 (accessed on 16 December 2021).

11. United Nations. General Assembly. Resolution 70/1. Transforming Our World: The 2030 Agenda for Sustainable Development, 2015, A/Res/70/1. Available online: https://www.un.org/en/development/desa/population/migration/generalassembly/ docs/globalcompact/A_RES_70_1_E.pdf (accessed on 16 December 2021).

12. European Financial Services Round Table. The Impact of Digital Transformation on Labour Best Practices and Policy Recommendations. 2020. Available online: https://www.efr.be/media/pmobjcst/132-1-efr-paper-on-digital-impact-on-labour.pdf (accessed on 24 October 2021).

13. European Commission. Platform on Sustainable Finance. EU Taxonomy \& Platform. Social Taxonomy Outreach. 2021. Available online: https:/ / ec.europa.eu/info/sites/default/files/business_economy_euro/banking_and_finance/documents/financeevents-210226-presentation-social-taxonomy_en.pdf (accessed on 24 October 2021).

14. European Commission. Platform on Sustainable Finance. Draft Report by Subgroup 4: Social Taxonomy. 2021. Available online: https: / / ec.europa.eu/info/sites/default/files/business_economy_euro/banking_and_finance/documents / sf-draftreport-social-taxonomy-july2021_en.pdf (accessed on 24 October 2021).

15. Global Reporting Initiative. The Global Standards for Sustainability Reporting. 2021. Available online: https://www. globalreporting.org/standards (accessed on 24 October 2021).

16. International Integrated Reporting Council (IIRC). International Integrated Reporting Framework. 2021. Available online: https:/ / integratedreporting.org/resource/international-ir-framework/ (accessed on 24 October 2021).

17. UNEP Finance Initiative, UNITED NATIONS Global Compact. Principles for Responsible Investment. 2006. Available online: https: / / www.unpri.org/ download?ac=10970 (accessed on 24 October 2021).

18. International Corporate Governance Network. ICGN Global Governance Principles. 2017. Available online: http://icgn.flpbks. com/icgn_global_governance_principles/ICGN_Global_Governance_Principles.pdf (accessed on 24 October 2021).

19. International Corporate Governance Network. ICGN Global Stewardship Principles. 2020. Available online: https://www.icgn. org/sites/default/files/ICGN\%20Global\%20Stewardship\%20Principles\%202020_0.pdf (accessed on 24 October 2021).

20. Investors Stewardship Group (ISG). The Stewardship Principles. Stewardship Framework for Institutional Investors. 2020. Available online: https://isgframework.org/wp-content/uploads/2020/07/ISG_Stewardship_Principles.pdf (accessed on 24 October 2021).

21. IESE-Penteo. Estudio IESE-Penteo Sobre Transformación Digital. 2020. Available online: https://media.iese.edu/research/pdfs/ ST-0546.pdf (accessed on 24 October 2021).

22. López, J.Z.; Ricart, J.E. Radiografía de la transformación digital en españa: Seis metacompetencias críticas. Harv. Deusto Bus. Rev. 2020, 303, 8-25.

23. Drucker, P.F. Economic tasks and risk-taking decisions. In Managing for Results; Routledge: London, UK, 1964.

24. Rappaport, A. Creating Shareholder Value: The New Standard for Business Performance; Free press: New York, NY, USA, 1986.

25. Copeland, T.E.; Koller, T.; Murrin, J. Valuation: Measuring and Managing the Value of Companies; Wiley Frontiers in Finance; Wiley: Hoboken, NJ, USA, 1990. [CrossRef]

26. Kaplan, R.S.; Norton, D.P. The balanced scorecard-measures that drive performance. Harv. Bus. Rev. 1992, 70, 71. [PubMed] 
27. Edvinsson, L.; Malone, M.S. Intellectual capital: Realizing your company's true value by finding its hidden brainpower. Res. Technol. Manag. 1997, 40, 59.

28. Sveiby, K.E. The intangible assets monitor. The Intangible Assets Monitor. J. Hum. Resour. Costing Account. 1997, 2, 7397. Available online: https://www.sveiby.com/files/pdf/the-intangible-assets-monitor.pdf (accessed on 24 October 2021). [CrossRef]

29. Paul, S.; Burton Rob, J.F. Defining terms for integrated (multi-inter-trans-disciplinary) sustainability research. Sustainability 2011, 3, 1090-1113. [CrossRef]

30. Price Waterhouse Coopers (pwc). Fundación Once, Inserta Empleo, Cofinanciadas por el Fondo Social Europeo, en el Marco del Programa Operativo de Inclusión Social y Economía Social (POISES) 2014-2020. Maria Tussy Flores y Carla Bonino Covas (Fundación ONCE). Virginia Carcedo Illera, Mar Medeiros Cuiña y Edurne Álvarez de Mon González (INSERTA Empleo). 2018. Available online: https://biblioteca.fundaciononce.es/publicaciones/colecciones-propias/programa-operativo/metodologiaisimpact-propuesta-metodologica-y (accessed on 16 December 2021).

31. Torres, M.; Paz, K.; Salazar, F. Tamaño de una muestra para una investigación de mercado. Boletín Electrónico 2006, 2, 1-13.

32. Inglehart, R.; Welzel, C. World Values Survey. 2020. Available online: http://www.worldvaluessurvey.org/wvs.jsp (accessed on 24 October 2021).

33. Cronbach, L.J. Coefficient alpha and the internal structure of tests. Psychometrika 1951, 16, 297-334. [CrossRef]

34. Likert, R. A technique for the measurement of attitudes. Arch. Psychol. 1932, 22, 55.

35. Massey, F.J., Jr. The kolmogorov-smirnov test for goodness of fit. J. Am. Stat. Assoc. 1951, 46, 68-78. [CrossRef]

36. Shapiro, S.S.; Wilk, M.B. An analysis of variance test for normality (complete samples). Biometrika 1965, 52, 591-611. [CrossRef]

37. Shapiro, S.S.; Francia, R. An approximate analysis of variance test for normality. J. Am. Stat. Assoc. 1972, 67, 215-216. [CrossRef]

38. Student. The probable error of a mean. Biometrika 1908, 1-25.

39. Rubio Hurtado, M.J.; Berlanga, V. Cómo aplicar las pruebas paramétricas bivariadas t de student y ANOVA en SPSS. REIRE.Rev. D'Innovació I Recer. En Educ. 2012, 5, 83-100. Available online: http:/ / hdl.handle.net/2445/45286 (accessed on 16 December 2021).

40. Nachar, N. The mann-whitney U: A test for assessing whether two independent samples come from the same distribution. Tutor. Quant. Methods Psychol. 2008, 4, 13-20. [CrossRef]

41. Mann, H.B.; Whitney, D.R. On a test of whether one of two random variables is stochastically larger than the other. Ann. Math. Stat. 1947, 18, 50-60. [CrossRef]

42. Kruskal, W.H.; Wallis, W.A. Use of ranks in one-criterion variance analysis. J. Am. Stat. Assoc. 1952, 47, 583-621. [CrossRef]

43. Benesty, J.; Chen, J.; Huang, Y.; Cohen, I. Pearson correlation coefficient. In Noise Reduction in Speech Processing; Springer: Berlin/Heidelberg, Germany, 2009; pp. 1-4.

44. Spearman, C. The proof and measurement of association between two things. Am. J. Psychol. 1904, 15, 72-101. [CrossRef]

45. Olsen, E. Rethinking value-based management. Handb. Bus. Strategy 2003, 4, 286-301. [CrossRef]

46. Bannister, R.J.; Jesuthasan, R. Finding your company's path to prosperity. Handb. Bus. Strategy 2000, 1, 285. [CrossRef]

47. Osterland, A. Grey matters: CFO's third annual knowledge capital scorecard. CFO 2001, 17.

48. Kindermann, B.; Beutel, S.; de Lomana, G.G.; Strese, S.; Bendig, D.; Brettel, M. Digital orientation: Conceptualization and operationalization of a new strategic orientation. Eur. Manag. J. 2020, 39, 645-657. [CrossRef] 